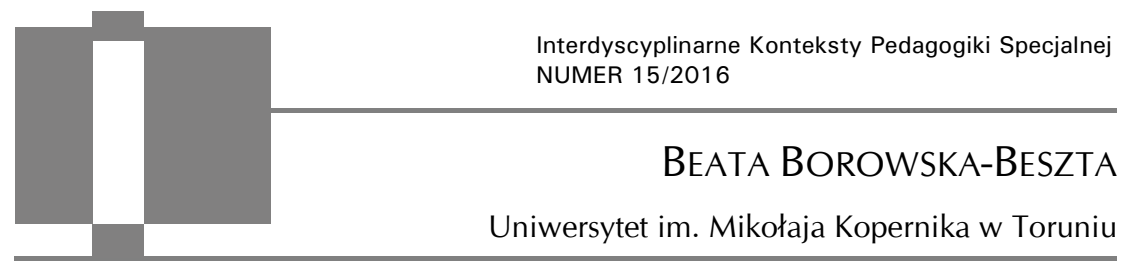

\title{
Wkład antropologii kulturowej w studia nad niepełnosprawnością
}

\begin{abstract}
Beata Borowska-Beszta, Wktad antropologii kulturowej w studia nad niepetnosprawnościa [Contribution of Cultural Anthropology to the Disability Studies]. Interdyscyplinarne Konteksty Pedagogiki Specjalnej, nr 15, Poznań 2016. Pp. 15-41. Adam Mickiewicz University Press. ISSN 2300-391X

Interdisciplinary studies on disability are conducted in the world by scholars from different disciplines and sub-disciplines, including special education. This article deals with an analysis of the evolution of the concept of disability studies and its' implementation in anthropology that was narrowed to cultural anthropology, primarily of American roots with references to British social anthropology. The basic question, which I answer from the perspective of the cultural anthropologists, is formulated as follows: why cultural anthropology is important in the disability studies? I give answers in the context of: ontological, epistemological, rhetorical and political issues. Anthropological analyzes are preceded by definitions of disability studies after Stteven aylor, Bonnie Shoultz, Pamela Walker; Colin Barnes; Dan Goodley; Sharon L. Snyder; David T. Mitchell and Ronald J. Berger.
\end{abstract}

KEY WORDS: cultural anthropology, disability studies, theoretical review

\section{Wprowadzenie}

Interdyscyplinarne studia nad niepełnosprawnością są prowadzone na świecie przez uczonych z różnych dyscyplin i subdyscyplin, włączając pedagogikę specjalną. Niniejszy artykuł odnosi się 
do analizy ewolucji koncepcji oraz realizacji studiów nad niepełnosprawnością w antropologii zawężonej do antropologii kulturowej głównie gruntu amerykańskiego z wzmiankami o antropologii społecznej na gruncie brytyjskim. Podstawowe pytanie, na które udzielam odpowiedzi z perspektywy samych antropologów kultury oraz mojej własnej - pedagoga specjalnego, jest sformułowane następująco: dlaczego antropologia kultury jest istotna $\mathrm{w}$ studiach nad niepełnosprawnością? Odpowiedzi udzielam w kontekstach: ontologicznym, epistemologicznym, retorycznym oraz politycznym. Kontekstowi aksjologicznemu poświęcę odrębne opracowanie. Analizy antropologiczne poprzedzam definicjami studiów nad niepełnosprawnością za Stevenem Taylorem, Bonnie Shoultz, Pamelą Walker ${ }^{1}$, Colinem Barnesem², Danem Goodleyem³, Sharon L. Snyder, Davidem T. Mitchellem ${ }^{4}$ i Ronaldem J. Bergerem ${ }^{5}$.

\section{Definiowanie studiów nad niepełnosprawnością}

Colin Barnes wskazuje, iż naukowe źródła ontologii studiów nad niepełnosprawnością wyrosły na fali krytyki społecznego modelu niepełnosprawności m.in. dlatego, że „twierdzi się, że podział pojęciowy między uszkodzeniem i niepełnosprawnością, na którym opiera się model społeczny, jest fałszywy"6. Ponadto Colin Barnes

${ }^{1}$ S. Taylor, B. Shoultz, P. Walker, Disability studies: Information and Resources http://thechp.syr.edu/wp-content/uploads/2013/10/Disability_Studies_2003_cur rent.pdf 2003 [dostęp: 7.04.2016].

2 C. Barnes, Disability Studies: what's the point? (Notes for a verbal presentation at the 'Disability Studies: Theory. Policy and Practice' Conference; University of Lancaster, September 4th. 2003). http://disability-studies.leeds.ac.uk/files/library/ Barnes-Whats-the-point.pdf [dostęp: 7.04.2016].

${ }^{3}$ D. Goodley, Disability Studies. An Interdisciplinary Introduction, Sage, London 2011.

4 S.L. Snyder, D.T Mitchell, Cultural Locations of Disability, University of Chicago Press, Chicago 2006.

${ }^{5}$ R.J. Berger, Introducing Disability Studies, Lynne Rienner Publishers, London 2013.

${ }^{6}$ C. Barnes, Disability Studies: what's the point?..., s. 10, [tłumaczenia wszystkich cytatów z anglojęzycznych publikacji w artykule są autorstwa Beaty Borowskiej-Beszty]. 
podkreśla, że „zniesienie barier nie rozwiąże problemów związanych z niepełnosprawnością, ponieważ niektóre problemy napotykane przez osoby $z$ niepełnosprawnością są powodowane przez uszkodzenie na planie somatycznym, a nie przez społeczeństwo"7. Kenny Fries ${ }^{8}$ podkreśla z kolei epistemologię studiów oraz istotę udziału w studiach nad niepełnosprawnością, niepełnosprawnych badaczy, mówiąc, że takie studia są dla ludzi z niepełnosprawnością sposobem i możliwością gapienia się i wytrzeszczania oczu na tych, którzy gapią się na nich. Definicję współczesnych studiów nad niepełnosprawnością wskazują m.in. Steven Taylor, Bonnie Shoultz i Pamela Walker9, którzy traktują je jako fenomen społeczny, kulturowy i polityczny. Autorzy uważają, że w przeciwieństwie do medycznych, klinicznych lub terapeutycznych perspektyw ujmowania niepełnosprawności studia nad niepełnosprawnością koncentrują się na sposobie, w jaki niepełnosprawność jest definiowana i reprezentowana w społeczeństwie. Dodam jeszcze w uzupełnieniu, że studia nad niepełnosprawnością koncentrują się również na definiowaniu i eksploracji reprezentacji niepełnosprawności w kulturze dominującej, kulturach niepełnosprawności oraz artefaktach i symbolach kulturowych ${ }^{10}$. Dla S. Taylora, B. Shoultz, P. Walker „studia nad niepełnosprawnością są tętniącym i zróżnicowanym terenem

7 Ibidem, s. 16.

${ }^{8}$ K. Fries, Staring back: The disability experience from the inside out, Plume, New York 1997.

${ }_{9}$ S. Taylor, B. Shoultz, P. Walker, op. cit.

${ }^{10}$ Dane opublikowałam m.in. w publikacjach: B. Borowska-Beszta, Niepetnosprawność w kontekstach kulturowych i teoretycznych, Oficyna Wydawnicza "Impuls”, Kraków 2012; B. Borowska-Beszta, Etnografia stylu życia kultury dorostych torunian z zaburzeniami rozwoju, Wydawnictwo Naukowe UMK, Torun 2013; B. Borowska-Beszta, Kultury niepetnosprawności w kontekstach teoretycznych i realiach badawczych szkice analizy strukturalnej http://www.pion.pl/artykuly/czytelnia/kultury-niepelno sprawnosci-w-kontekstach-teoretycznych-i-realiach-badawczych-szki 2014 [dostęp: 30.04.2016]. Oswajanie odmienności kulturowej. 11 Raportów z polskich jakościowych badań pedagogicznych $i$ andragogicznych, red. B. Borowska-Beszta, WBWOmniScriptum, Saarbrücken 2016. 
lub obszarem badawczym"11. Autorzy potwierdzają, że mają na myśli interdyscyplinarne oraz multidyscyplinarne studia nad fenomenem. Żadna pojedyncza dyscyplina, zdaniem autorów, nie może sobie uzurpować prawa do prowadzenia studiów nad niepełnosprawnością. Badacze wskazują, że studia nad niepełnosprawnością to „teren badawczy dla dyscyplin naukowych, takich jak historia, socjologia, literatura, nauki polityczne, prawo, ekonomia, studia kulturowe, antropologia, geografia, filozofia, teologia, studia gender, medioznawstwo i studia nad komunikacją oraz sztuka"12. Moim zdaniem autorzy powyższego uporządkowania, wykluczyli niesłusznie i nazbyt pospiesznie pedagogikę jako dyscyplinę oraz szczególnie jej subdyscyplinę pedagogikę specjalną, w których można prowadzić i de facto prowadzone są studia nad niepełnosprawnością zagranicą i w Polsce. Jednakże mam na myśli badania prowadzone albo przez akademików realizujących je w teoretycznych modelach społecznego i kulturowego konceptualizowania niepełnosprawności, umożliwiających istotny udział głosu środowisk z niepełnosprawnością i kultur niepełnosprawności albo przez polskich akademików, pedagogów specjalnych mających niepełnosprawności np. fizyczne, sensoryczne i inne, do których bezpośrednio odnoszą się w badaniach własnych, niekiedy projektowanych z innych perspektyw oraz wpisujących się profesjonalnym działaniem $\mathrm{w}$ interdyscyplinarne studia nad niepełnosprawnością. $\mathrm{W}$ jaki sposób S. Taylor, B. Shoultz, P. Walker ${ }^{13}$ uzasadniają to, czym studia nad niepełnosprawnością nie są? Autorzy piszą „(nie są ani medycyną, ani rehabilitacją, edukacją specjalną, kinezyterapią, terapią zajęciową i profesjami skierowanymi na wyleczenie, zapobieganie lub terapię niepełnosprawności)"14. Komentując na bieżąco powyższy zakres, trudno się, moim zdaniem, zgodzić na wykluczenie ze studiów nad niepełnosprawnością subdyscypliny, jaką jest pedago-

\footnotetext{
11 S. Taylor, B. Shoultz, P. Walker, op. cit., s. 1.

12 Ibidem.

13 Ibidem.

14 Ibidem.
} 
gika specjalna z jednego prostego powodu - otóż procesy edukacyjne i edukacja istnieją w podstawowych systemach dowolnej kultury, stąd trudno pominąc procesy edukacyjne w studiach nad niepełnosprawnością pojmowanych jako studia kulturowe. Można jednakże przyznać rację S. Taylorowi, B. Shoultz i P. Walker w analizowanej publikacji, iż priorytetowe kierunki badań $\mathrm{w}$ studiach nad niepełnosprawnością są działaniami wykluczającymi w celach badawczych postępowania lecznicze, naprawcze, terapeutyczne i w taki sposób ingerujące w tożsamość człowieka z niepełnosprawnością oraz oparte na konceptualizacji niepełnosprawności zgodnie z modelem medycznym. Błędnie jednak, moim zdaniem, autorzy założyli, że ontologia pedagogiki specjalnej uwzględnia jedynie perspektywę medycznego modelu niepełnosprawności z pominięciem kulturowego, społecznego, interakcyjnego, praw człowieka itp. S. Taylor, B. Shoultz, P. Walker ${ }^{15}$ podkreślają natomiast, że studia nad niepełnosprawnością wpisują się $\mathrm{w}$ socjologiczną koncepcję niepełnosprawności odniesioną do modelu mniejszości precyzującego status osób niepełnosprawnych jako grup mniejszości kształtujących ich doświadczenia w społeczeństwie. Akademicy zgadzają się również z dwiema innymi koncepcjami konceptualizowania niepełnosprawności w studiach nad niepełnosprawnością. Z jednej strony są bowiem badacze niepełnosprawności postrzegający ją w perspektywach konstruktu kulturowego, tożsamości kulturowej, czyli istniejących kultur niepełnosprawności (np. Colin Barnes i Geof Mercer $^{16}$, Sharan E. Brown ${ }^{17}$, Beata Borowska-Beszta ${ }^{18}$ ) lecz z drugiej

\section{Ibidem.}

${ }^{16}$ C. Barnes, G. Mercer, Disability Culture: Assimilation or Inclusion?, [w:] Handbook of Disability Studies, Sage Publications, red. G.L. Albrecht, K. Seelman, M. Bury, Inc. London, Londyn 2001, s. 515-534.

17 S.E. Brown, What Is Disability Culture?, “Disability Studies Quarterly”, Spring 2002, Volume 22, No. 2, s. 34-50.

18 Dane o kulturach niepełnosprawności opublikowałam kolejno m.in. w publikacjach: B. Borowska-Beszta, Niepetnosprawność w kontekstach...; B. Borowska-Beszta, Etnografia stylu życia kultury dorostych...; B. Borowska-Beszta, Kultury niepetnosprawności w kontekstach...; Oswajanie odmienności kulturowej... 
strony są i inni, postrzegający ją jako etykietę i konstrukt społeczny (m.in. Tom Shakespeare ${ }^{19}$, Nicholas Watson ${ }^{20}$, Elżbieta Zakrzewska-Manterys ${ }^{21}$, Agnieszka Kumaniecka-Wiśniewska ${ }^{22}$ ).

Studia nad niepełnosprawnością definiuje kolejno Colin Barnes $^{23}$. Autor zauważa krytycznie, że takie „studia są badaniami odrębnych sił ekonomicznych, politycznych i kulturowych wspierających i podtrzymujących niepełnosprawność (jak podkreślono w Ruchu Praw Osób Niepetnosprawnych) po to, aby uzyskać znaczącą i praktyczną wiedzę na temat dalszego zwalczania wspomnianych sił"24. Definicję studiów nad niepełnosprawnością wskazuje kolejno Dan Goodley w książce pt. Disability studies. Autor definiuje je jako zmianę paradygmatu: od niepełnosprawności pojmowanej „jako osobiste i kłopotliwe położenie do niepełnosprawności, jako patologii społecznej" ${ }^{25}$. Autor referuje relacje wobec niepełnosprawności następująco:

osoby z niepełnosprawnością były znienawidzone, traktowane, jako obiekty egzotyczne, obiekty litości, traktowania protekcjonalnego i ignorancji. Niepełnosprawność wzbudzała także podziw, ciekawość, fascynację i sympatię. Studia nad niepełnosprawnością odpowiadają badawczo na te akty życia politycznego i kulturalnego ${ }^{26}$.

Kolejną definicję studiów, którą włączam do rozważań w niniejszym artykule, skonstruowali Sharon L. Snyder, David T. Mitchell,

19 T. Shakespeare, Cultural representations of disabled people: dustbins for disavowal?, "Disability and Society" 1994, 9(3), s. 283-299.

${ }^{20}$ T. Shakespeare, N. Watson, The social model of disability: an outdated ideology?, “Journal Research in Social Science and Disability” 2002, Vol. 2, s. 9-28.

${ }^{21}$ E. Zakrzewska-Manterys, Down i zespót wattpliwości. Studium z socjologii cierpienia, Wydawnictwo Naukowe Semper, Warszawa 1995; E. Zakrzewska-Manterys, Upośledzeni umysłowo. Poza granicami człowieczeństwa, Wydawnicwo Naukowe UW, Warszawa 2010.

22 A. Kumaniecka-Wiśniewska, Kim jestem? Tożsamość kobiet upośledzonych umystowo, Wydawnictwo Akademickie Żak, Warszawa 2005.

${ }^{23}$ C. Barnes, Disability Studies: what's the point?...

${ }^{24}$ Ibidem, s. 10 [dostęp: 7.04.2016].

25 D. Goodley, Disability Studies. An Interdisciplinary Introduction, Sage, London 2011, s. XI.

${ }^{26}$ Ibidem. 
a przywołał Ronald J. Berger ${ }^{27}$. Autorzy uważają, że studia nad niepełnosprawnością stanowią interdyscyplinarne pole badań obejmujących reprezentacje pochodzące $\mathrm{z}$ nauk społecznych i humanistycznych, rehabilitacji medycznej oraz profesji edukacyjnych, istotnych dla zrozumienia ludzkości28. Jak można dostrzec, z powyżej wskazanych definicji wyłania się przedmiot interdyscyplinarnych badań, które $\mathrm{w}$ istotny sposób podkreślają badanie relacji i oddziaływań społecznych i kulturowych kultur, jednakże z uwzględnieniem badania skali makro-procesów społeczno-kulturowych oraz z uwzględnieniem wybranych systemów kultury, jak ekonomia i polityka. Wskazane definicje analizowane powyżej preferują procesy dotyczące studiów prowadzonych w skali makrospołecznej i makro-kulturowej. Analizowane koncepcje, z wyjątkiem Sharon L. Snyder, Davida T. Mitchella ${ }^{29}$, nie wskazują systemu kultury, jakim jest edukacja ani jej procesów, jako gruntu odniesienia empirycznego studiów nad niepełnosprawnością.

\section{Antropologiczne studia nad niepełnosprawnością}

\section{Kontekst ontologiczny}

Devva Kasnitz i Russell Shuttleworth uważają, że „etnologiczne podejście do fenomenów odmienności, różnicy, inności oraz postrzegania innych jako tematu badań jest unikatowym aspektem antropologii, powodującym naturalne zaangażowanie się tej dyscypliny w studia nad niepełnosprawnością" ${ }^{30}$. Autorzy zauważają, że w ogóle dla badaczy z obszaru nauk społecznych i humanistycz-

27 R.J. Berger, op. cit.

28 S.L. Snyder, D.T. Mitchell, Cultural Locations of Disability, University of Chicago Press, Chicago 2006.

29 Ibidem.

${ }^{30}$ D. Kasnitz, R. Shuttleworth, Introduction: Anthropology in Disability Studies, "Disability Studies Quarterly", Summer 2001, Vol. 21, No. 3, s. 2-17. 
nych osoby z niepełnosprawnością lub chorzy stają się przykładami odmienności, inności. Coś, co odróżnia i wyróżnia antropologię kulturową w kontekstach epistemologicznych, można powiązać ze stwierdzeniem D. Kasnitz i R. Shuttlewortha31, że antropolodzy poznają innych, aby odnaleźć siebie. Autorzy dodają, że odmienność fenomenu niepełnosprawności, identyfikowana pierwotnie przez inne dyscypliny, włącza badawczo również doświadczonych etnografów poszukujących odrodzenia ich poczucia oraz rozumienia doświadczeń innego w znanym terenie badawczym. Ponadto, zdaniem D. Kasnitz i R. Shuttlewortha, „badania antropologiczne nad niepełnosprawnością interesują antropologów jeszcze z innych powodów: poszukiwania odmienności i inności bliżej domu oraz sama kategoria niepełnosprawności konstruowana społecznie i kulturowo z istotnymi implikacjami, w jaki społeczeństwa różnorodnie dystrybuują władzę"32.

\section{Aspekt pierwszy}

Antropologia kulturowa to subdyscyplina antropologii zajmująca się badaniem kultury i jej procesów, w tym procesów związanych z niepełnosprawnością ludzką. Antropolodzy kultury podjęli próby zrozumienia i naukowego zbadania niepełnosprawności zanim w Stanach Zjednoczonych zaczęto rozwijać i oficjalnie ustanowiono interdyscyplinarne studia nad niepełnosprawnością. Chronologicznie analizując problem związków dyscypliny i interdyscyplinarnego pola badań, można dostrzec dane o tym, że studiowanie niepełnosprawności w sposób antropologiczny ma swe źródła i związki w konfliktach militarnych i ich skutkach oraz wiąże się badaniem niepełnosprawności wśród ludności cywilnej i wojska, generowanych przez konflikty militarne i wojny. Pomijam tu obszerną historię badań antropologicznych uwzględniających narracje i relacje z wojen perskich rejestrowanych przez ojca antropologii kulturowej, geografii i historii Herodota z Halikarnassu w V w. p.n.e., bo-

\footnotetext{
31 Ibidem.

32 Ibidem.
} 
wiem, zdaniem antropolog kulturowej Heather Battles ${ }^{33}$, to wojna w Wietnamie poprzedziła ustanowienie amerykańskich, interdyscyplinarnych studiów nad niepetnosprawnością. Autorka pisze, że

przed utworzeniem studiów nad niepełnosprawnością jako interdyscyplinarnego pola badań, istniało wśród antropologów zainteresowanie badaniami związanymi ze społecznymi kierunkami badań nad niepełnosprawnością w ramach Ruchu Praw Osób Niepełnosprawnych (Disability Rights Movement). Działania badawcze rozpoczęto od momentem powrotu do USA w 1975 r. weteranów wojny w Wietnamie, którzy stali się niepełnosprawni ${ }^{34}$.

Antropolodzy kultury dzięki prowadzonym badaniom etnograficznym, obserwacji uczestniczącej i pracom terenowym mogli mieć wkład w procesy rehabilitacji weteranów. Heather Battles kontynuuje, że odrębne pole badań, jako interdyscyplinarne studia nad niepełnosprawnością, zostało utworzone oficjalnie w $1982 \mathrm{r}$. przez Towarzystwo Studiów nad Niepełnosprawnością (Society for Disability Studies) ${ }^{35}$. Sięgając natomiast wstecz do początku XX w. i pierwszych zainteresowań badawczych antropologów kultury problematyką niepełnosprawności ludzkiej bez kontekstu interdyscyplinarnych studiów nad niepełnosprawnością, chciałabym przywołać badania antropologiczne nad epilepsją z 1934 r. prowadzone przez Ruth Benedict ${ }^{36}$, ponadto Jane R. Hanks, L.M. Hanks Jr ${ }^{37}$, którzy badali niepełnosprawność fizyczną w latach 60. XX w. oraz badania etnograficzne Robert B. Edgertona dotyczące osób etykietowaych w Stanach Zjednoczonych jako upośledzonych mentally retarded -

${ }^{33} \mathrm{H}$. Battles, Toward Engagement: Exploring the Prospects for an Integrated Anthropology of Disability, "vis-à-vis: Explorations in Anthropology", 2011, Vol. 11, No. 1, s. 107-124.

34 Ibidem, s. 108.

35 Ibidem, s. 109.

36 R. Benedict, Anthropology and the Abnormal, "Journal of General Psychiatry", 1934,10 , s. 59-80.

37 J.R. Hanks, L.M. Hanks, The Physically Handicapped in Certain Non-Occidental Societies, "Journal of Social Issues", 1948, Volume 4, Issue 4, s. 11-20. 
upośledzonych umysłowo ${ }^{38}$. Następnie w latach 60 . XX w. brytyjska antropolog społeczna Mary Douglas ${ }^{39}$ opisała pięć uniwersalnych w kulturach podejść do anomalii. Inne ważne studia antropologiczne nad niepełnosprawnością prowadziła nad achondroplazją - karłowatością w latach 80. m.in. Joan Ablon ${ }^{40}$. Z kolei w latach 90. $\mathrm{w}$ amerykańskich badaniach nad niepełnosprawnością warto odnotować prace badawcze Michaela Angrosino, znanego w Polsce uczonego amerykańskiego, autora podręcznika metodologicznego pt. Badania etnograficzne $i$ obserwacyjne 41 . M. Angrosino prowadził badania etnograficzne fenomenu niepełnosprawności w kulturze Zachodu, w Stanach Zjednoczonych, poświęcając uwagę problemom dorosłości, a także seksualności osób z niepełnosprawnością intelektualną, ponadto badał koncepcje deinstytucjonalizacji ${ }^{42}$. Antropolodzy prowadzili również studia nad rehabilitacją osób z niepełnosprawnością. Wśród nich znajdują się badania prowadzone przez Davida Hershensona ${ }^{43}$. Kolejne interesujące badania antropologiczne dotyczące niepełnosprawności intelektualnej prowadzili na gruncie antropologii amerykańskiej Ray McDermott i Herve Varen-

${ }^{38}$ R.B. Edgerton, A Patient Elite: Ethnography in a Hospital for the Mentally Retarded, "American Journal of Mental Deficiency" 1963, 68, s. 372-497; R.B. Edgerton, The Cloak of Competence: Stigma in the Lives of the Mentally Retarded, University of California Press, Berkeley 1967.

${ }^{39}$ M. Douglas. Czystość i zmaza, PIW, Warszawa 2007.

$40 \mathrm{~J}$. Ablon, Little people in America: The social dimensions of dwarfism, Praeger, New York 1984; J. Ablon, Living with difference: Families with dwarf children, Praeger, New York 1988.

${ }^{41}$ M. Angrosino, Badania etnograficzne i obserwacyjne, PWN, Warszawa 2010.

$42 \mathrm{M}$. Angrosino napisał kluczowe publikacje poświęcone niepełnosprawności intelektualnej, wśród nich: M. Angrosino, Metaphors of Stigma: How Deinstitutionalized Mentally Retarded Adults See Themselves, "Journal of Contemporary Ethnography" 1992, 21(2) s. 171-199; M. Angrosino, The Ethnography of Mental Retardation: An Applied Perspective, "Journal of Contemporary Ethnography" 1997, 26(1), s. 98-109; M. Angrosino Opportunity House: Ethnographic Stories of Mental Retardation, Altamira Press, Walnut Creek 1998.

43 D. Hershenson, Conceptions of Disability: Implications for Rehabilitation. "Rehabilitation Counseling Bulletin" 1992, 35(3), s. 154-160. 
ne ${ }^{44}$ (1998). W kolejnych latach uczonymi, którzy napisali ważne publikacje i raporty ze studiów antropologicznych nad niepełnosprawnością są Benedict Ingstad i Susan Reynolds Whyte ${ }^{45}$ i ich książka pt. Disability in Local and Global Worlds. Studia nad niepełnosprawnością, mimo iż mają zwolenników wśród antropologów i są stale prowadzone, zdaniem Davida Hershensona ${ }^{46}$ bywają marginalizowane na tle zainteresowań uczonych całej subdyscypliny, jaką jest antropologia kulturowa.

\section{Aspekt drugi}

Antropologia kultury i jej teoria posługuje się terminami i koncepcjami odmiennościt7 odmienności psychosomatycznej48 koncepcją innego, która nota bene jest wieloletnią klamrą tytułu konferencji organizowanej przez Uniwersytet im. Adama Mickiewicza na Wydziale Studiów Edukacyjnych. Ta subdyscyplina współcześnie odrzuca etnocentryzm, supremację, hegemoniczność badacza, jednolitość czy monolityczność konstruktów niepełnosprawności oraz traktuje wskazane kategorie odmienności i inności jak szczególnie podmioty, które je semantycznie stanowią z należnym im uszanowaniem. Owo uszanowanie podmiotów z niepełnosprawnością szczególnie podkreślała Aleksandra Rzepkowska, antropolog kultury podczas własnego referatu konferencji pt. Odmienność w kulturze w dniach 28-29 września 2015 r., zorganizowanej przez Katedrę Etnologii i Antropologii Kulturowej Uniwersytetu im. Mikołaja Kopernika w Toruniu.

${ }^{44}$ R. McDermott, H. Varenne, Adam, Adam, Adam, and Adam: The Cultural Construction of a Learning Disability. In Successful Failure: The School America Builds, [w:] Successful Failure: The School America Builds, red. H. Varenne, R. McDermott, CO: West-view Press, Boulder 1999, s. 25-44.

45 B. Ingstad, S.R. Whyte, Disability in Local and Global Worlds, Univ. Calif. Press, Berkeley 2007.

46 D. Hershenson, Toward a Cultural Anthropology of Disability and Rehabilitation, “Counseling Bulletin" 2000, 43(3), s. 150-157.

47 A. Perzanowski, Odmieńcy. Antropologiczne studium dewiacji, Wydawnictwo DiG, Warszawa 2009.

48 Oswajanie odmienności psychosomatycznej... 


\section{Aspekt trzeci}

Antropolodzy kultury, zdaniem D. Hershensona ${ }^{49}$ definiują niepełnosprawność i wyraźnie odróżniają ją jako kategorię teoretyczną inną, od pojęcia choroba, schorzenie, którymi zajmuje się badawczo antropologia medyczna. Nie wykluczają oni aspektów biomedycznych w wymiarze semantyki fenomenu, lecz dodatkowo wskazują konfuzje terminologiczne napotykane w antropologii kulturowej, a dotyczące studiów nad niepełnosprawnością. Wybrane definicje niepełnosprawności precyzują D. Hershenson ${ }^{50}$, J.ani Klotz ${ }^{51}$, Heather Battles ${ }^{52}$, Vikramendra Kumar'53 i inni. V. Kumar, cytując Jani Klotz, pisze, że niepełnosprawność jest kompleksowym fenomenem społecznym, kulturowym i biomedycznym ${ }^{54}$. Heather Battles ${ }^{55}$ precyzuje uniwersalizm doświadczeń ludzkich i światowy zakres wątków kulturowych w definiowaniu niepełnosprawności, mówiąc, że uszkodzenie (impairment) i niepełnosprawność (disability) są fundamentalnymi ludzkimi doświadczeniami w różnych kulturach. Russell Shuttleworth i Devva Ksnitz piszą z kolei, że „pomimo wzrastającej uwagi na problemy kluczowe niepełnosprawności w antropologii, antropologia niepełnosprawności cały czas doświadcza terminologicznej konfuzji dotyczącej nadmiernych teoretycznych uproszczeń oraz radykalnie relatywistycznych uprzedzeń, które są przeciwstawne podejściom

${ }^{49}$ D. Hershenson, Toward a Cultural..., s. 150-157.

50 Ibidem.

51 J. Klotz, The Culture Concept: Anthropology, Disability Studies and Intellectual Disability, paper presented to Disability Studies and Research Institute Symposium, "Disability at the Cutting Edge: A Colloquium to Examine the Impact on Theory, Research and Professional Practice," University of Technology, 2003. http://www.transforming. cultures.uts.edu.au/pdfs/new_paths_klotz.pdf, za: B. Borowska-Beszta, Niepetnosprawność w kontekstach...

52 H. Battles, op. cit., s. 107-124.

53 V. Kumar, Anthropological Perspective of Disability, "International Journal of Information Research and Review" 2016, Vol. 03, Issue, 02, s. 1892-1901.

54 Ibidem, s. 1894.

${ }^{55}$ H. Battles, op. cit., s. 107. 
krytycznym"56. Autorzy mają na myśli również konfuzje dotyczące zamiennego stosowania przez antropologów pojęć uszkodzenie i niepetnosprawność.

\section{Aspekt czwarty}

Antropologia kultury uwzględnia biomedyczne aspekty, lecz poszukuje kulturowych definicji i koncepcji niepełnosprawności odniesionych do relacji kultury dominującej i kultur niepełnosprawności. Jednocześnie antropolodzy kultury krytykują nadmierną medykalizację procesów konstruowania niepełnosprawności. Aleksandra Rzepkowska ${ }^{57}$, polska antropolog kultury z UMK w Toruniu, napisała krytyczny tekst poświęcony m.in. negatywnym skutkom diagnoz medycznych, po badaniach terenowych własnych z udziałem osób z zespołem Aspergera. Autorka pisze:

ważną cechą medycznych etykiet diagnostycznych jest też to, że choć (tak jak i inne etykiety) są one fundowane społecznie, a więc mają charakter względny, uproszczony, a czasem arbitralny i mogą być nietrafne, to jednak silnie "przyklejają się" do osoby - bardzo trudno się ich pozbyć. Nawet przy znacznej poprawie funkcjonowania oraz stopniowego przystawania do społecznych standardów, osoba z rozpoznanym zespołem Aspergera i w taki sposób identyfikowana przez otoczenie, prawdopodobnie zawsze narażona będzie na dystans i nieufność 58 .

Autorka wskazuje ponadto, iż trzeba wiedzieć, że „diagnoza może stać się główną siłą napędową innego destrukcyjnego procesu, jakim jest medykalizacja własnej osoby" 59 .

Z tych i innych rozważań autorki z 2014 r. wypływają cenne, choć wcale nie nowe wnioski dla pedagogów specjalnych i pedago-

${ }^{56}$ R. Shuttleworth, D. Kasnitz, Stigma, community, ethnography: Joan Ablon's contribution to the anthropology of impairment/disability, "Medical Anthropology" 2004, 182, s. 153.

57 A. Rzepkowska, Zespót Aspergera - społeczno-kulturowe konsekwencje diagnozy, „Zeszyty Wiejskie" 2014, 14, t. 19, s. 143-153.

58 A. Rzepkowska, op. cit., s. 149.

59 Ibidem. 
gicznych studiów nad niepełnosprawnością, o potrzebie włączania dyscyplin uwzględniających inne sposoby konceptualizowania niepełnosprawności niż medyczno-kliniczne oraz o potrzebie badań procesów medykalizacyjnych. Do analogicznych wniosków doszło uprzednio wielu uczonych pracujących naukowo w społecznym i kulturowym modelach niepełnosprawności z dyscyplin takich jak antropologia kulturowa: David Hershenson ${ }^{60}$, Devva Kassnitz, Russell Shouttleworth ${ }^{61}$, Jani Klotz ${ }^{62}$, Heather Battles ${ }^{63}$ oraz socjologia z przedstawicielami takimi jak Colin Barnes ${ }^{64}$, Colin Barnes i Geof Mercer $^{65}$ Tom Shakepreare ${ }^{66}$ czy wreszcie przedstawiciele polskiej pedagogiki specjalnej od lat 90 . XX w. prowadzący badania nad teoretycznym konceptualizowaniem niepełnosprawności i rehabilitacji oraz edukacji osób z niepełnosprawnością. Problemowi związków antropologii kulturowej, jako teoretycznej perspektywie badań oraz jej empirycznej warstwie, czyli metodologii, a także aplikacji terenowych badań etnograficznych, nad niepełnosprawnością poświęcałam uprzednio uwagę w publikacjach z lat 1999-2017.

\section{Aspekt piaty}

Antropologia kulturowa uwzględnia Boasowską zasadę relatywizmu kulturowego w konceptualizowaniu niepełnosprawności, co oznacza, że sama niepełnosprawność, jej semantyczny zakres, pochodzenie i przyczyny, sposoby jej interpretacji oraz postępowania wobec niej będą postrzegane i rozumiane odmiennie w różnych kulturach. Inaczej będą rozumiane w kulturach arabskich np. Jordanii,

${ }^{60}$ D. Hershenson, Toward a Cultural Anthropology of Disability and Rehabilitation, “Counseling Bulletin" 2000, 43(3), s. 150- 157.

${ }^{61}$ D. Kassnitz, R. Shuttleworth, op. cit.

62 J. Klotz, op. cit.

${ }^{63}$ H. Battles, op. cit., s. 107-124.

${ }^{64}$ C. Barnes, Disabling Imagery And The Media. An Exploration of the Principles for Media Representations of Disabled People. http://disability-studies.leeds.ac.uk/files/ library/Barnes-disabling-imagery.pdf 1992 [dostęp: 7.04.2016].

65 C. Barnes, G. Mercer, Niepetnosprawność, Wydawnictwo Sic!, Warszawa 2008.

66 T. Shakespeare, Cultural representations of disabled people..., s. 283-299; T. Shakespeare, The Disability Reader: Social Science Perspectives, Cassell, London 1998. 
Arabii Saudyjskiej, inaczej w kulturze Japonii, Singapurze, Indiach czy państwach kultury Zachodu. Inaczej będą konceptualizowane wskazane problemy niepełnosprawności w kulturach zawodowych, kultur dominujących. Innych problemów związanych dysfunkcją, niepełnosprawnością, aż do karōshi (śmierci z przepracowania) doświadczą bieznesmani z Japonii, a innych biznesmani z Polski. Czym innym będzie niepełnosprawność i wynikające z niej konsekwencje życiowe dla członków organizacyjnych kultur wojskowych ${ }^{67}$, mam na myśli np. weteranów wojennych wojny w Wietnamie, weteranów współczesnych konfliktów zbrojnych na Bliskim Wschodzie, czym innym np. dla członków polskiej organizacji Stowarzyszenie „Rodzina Wojskowa”. Inna będzie kulturowa koncepcja niepełnoprawności ofiar ataków terrorystycznych w Państwie Islamskim (Islamic State) IS, a inna poza fundamentalistami z IS. Inną koncepcję niepełnosprawności dziecka będą miały radykalne środowiska feministyczne lub kultury aborcyjne na świecie i w Polsce, a inną środowiska i kultury pro-life. Czym innym będzie niepełnosprawność dla kultur akademickich - pedagogów specjalnych, a czym innym dla członków kultur niepełnosprawności ${ }^{68}$ itd. Te właśnie niuanse i problemy wyłaniające się na styku niepełnosprawności, kultury, polityki i ekonomii oraz systemów kultury takich jak język, edukacja, sztuka, religia (sacrum) są przedmiotem zainteresowań antropologicznych w studiach nad niepełnosprawnością, lecz także interesują pedagogów w pedagogicznych studiach nad niepełnosprawnością.

W 1994 r. Danuta Pękala-Gawędzka ${ }^{69}$ pisała o relatywizmie, odniesionym co prawda do kategorii stanowiących oś zainteresowań

${ }^{67}$ B. Borowska-Beszta, Metodologiczne konteksty badań kulturowych w obszarze andragogiki specjalnej, „Rocznik Andragogiczny” 2009, s. 110-123.

68 B. Borowska-Beszta, Kultury niepetnosprawności w kontekstach teoretycznych i realiach badawczych - szkice analizy strukturalnej, http://www.pion.pl/artykuly/czytelnia/ kultury-niepelnosprawnosci-w-kontekstach-teoretycznych-i-realiach-badawczych-szki 2014 [dostęp: 30.04.2016]; B. Borowska-Beszta, Aborcja eugeniczna (aborcja ze względu na niepetnosprawność) w opiniach polskich studentów studiów uniwersyteckich II. stopnia na kierunku pedagogika specjalna: Raport z etnograficznego studium przypadku [Raport $\mathrm{z}$ badań w toku wydawniczym].

${ }^{69}$ D. Pękala-Gawędzka, Antropologia medyczna a etnofarmakologia, „Lud” 1994, t. 77, s. 13-21. 
naukowych antropologii medycznej, ale jej uwagi są istotne również i analogiczne, w kontekstach pojęcia niepełnosprawności, stanowiącego kategorię badawczą antropologii kulturowej. Autorka pisze, że

badacze od dawna zwracali uwagę na zróżnicowanie pojęć zdrowia, normalności, choroby. Okazało się, że kategorie te, nie mają treści uniwersalnej, są zrelatywizowane kulturowo. Zjawiska uważane w jednej kulturze za symptomy choroby, w innej przeciwnie - mogą być oznakami zdrowia, a w jeszcze innej - nie mieć żadnego znaczenia dla oceny zdrowia ${ }^{70}$.

Powyższe uwagi dotyczące relatywizmu niepełnosprawności analizowałam na przykładzie w publikacji z 2012 r. przy okazji omawiania koncepcji brokeringu kulturowego i niepełnosprawności wśród imigrantów z Azji do Stanów Zjednoczonych ${ }^{71}$.

\section{Aspekt szósty}

Antropologia kulturowa uwzględnia ogląd i analizy fenomenu niepełnosprawności i postępowania wobec niej w kontekstach odmiennych procesów kulturowych i idiomatyczności odrębnych kultur. Oznacza to, że polskie dziecko z niepełnosprawnością może zostać porzucone emocjonalnie i fizycznie przez rodziców (przed lub) po urodzeniu, ale istnieje mniejsze prawdopodobieństwo, że (zdrowi psychicznie) polscy rodzice oskarżą dwulatka o czary, "złe oko" oraz skażą na głód i powolne umieranie, jak to się dzieje na ulicach afrykańskich wiosek ${ }^{72}$. Z kolei analogicznie ze względów kulturowych, obyczajowych (ale i prawnych) żadna polska kobieta z zespołem Downa mająca starszą pełnosprawną siostrę nie ma analogicznych szans na zamęście i nie zostanie w Polsce drugą żoną męża pełnosprawnej siostry, jak to się dzieje niekiedy w kulturach arabskich na Bliskim Wschodzie i poligamicznych małżeństwach aranżowanych.

70 Ibidem, s. 16.

71 B. Borowska-Beszta, Niepetnosprawność w kontekstach...

72 A. Cimpric, UNICEF WCARO, Dakar https://www.unicef.org/wcaro/wca ro_children-accused-of-witchcraft-in-Africa.pdf April 2010 [dostęp: 7.04.2016]. 
Ponadto w Polsce jest bardzo mało prawdopodobne, że kobieta $\mathrm{z}$ niepełnosprawnością intelektualną zostanie pod przymusem wydana za mąż (forced marriage), co ma miejsce w kulturach arabskich ${ }^{73}$. Mimo iż wskazane powyżej przykłady bywają badane, dyskutowane, krytykowane oraz budzą wiele wątpliwości (zwłaszcza małżeństwa zawierane pod przymusem), zilustrowany sposób wchodzenia w aranżowane i poligamiczne związki małżeńskie pełnosprawnego rodzeństwa daje $\mathrm{w}$ innej tradycji kulturowej status żony siostrze z zespołem Downa oraz zabezpieczenie bytu do śmierci. Z kolei problem relatywizmu kulturowego w obrębie samych kultur niepełnosprawności w kulturze Zachodu wskazałam w tekście, pt. Kultury niepetnosprawności w kontekstach teoretycznych $i$ realiach badawczych szkice analizy strukturalnej74, gdzie dokonywałam analizy strukturalnej wybranych kultur niepełnosprawności wraz z omówieniem ich symboliki. Przykładem mogą być odmienne symbole lingwistyczne i artefakty, z jakich korzystają uczestnicy danych kultur, inne np. w kulturach osób z niepełnosprawnością fizyczną i somatyczną, a zupełnie inne w kulturach osób z niepełnosprawnością intelektualną.

\section{Kontekst epistemologiczny}

\section{Aspekt pierwszy}

Antropologia kulturowa jako subdyscyplina naukowa angażuje procesy uczestnictwa badacza w terenie i korzystanie z paradygmatu badawczego partycypacyjnego i konstruktywistycznego ${ }^{75}$.

${ }^{73}$ IDA submission for the joint General Comment/Recommendation of the Committee on the Rights of the Child and the Committee on the Elimination of Discrimination against Women on harmful practices http://www.ohchr.org/Docu ments/HRBodies/CEDAW/HarmfulPractices/InternationalDisabilityAlliance.pdf [dostęp: 7.04.2016].

74 B. Borowska-Beszta, Kultury niepetnosprawności w kontekstach...

75 E. Guba., Y.S. Lincoln, Competing paradigms in qualitative research, [w:] N.K. Denzin, red. Y.S. Lincoln, Handbook of qualitative research, CA Sage, Thousand Oaks 1994, s. 105-117. 


\section{Aspekt drugi}

Antropologia kulturowa umożliwia prowadzenie studiów kulturowych i badanie problemów odniesionych do relacji kultury dominującej wobec fenomenów niepełnosprawności. Interesujące są w tym kontekście badania Mary Douglas i jej pięć koncepcji uniwersalnych postaw kultury wobec anomalii. Wśród nich są podejścia od (1) interpretacji anomalii, (2) fizycznego kontrolowania, (3) unikania, (4) etykietowania anomalii jako zagrożenia, (5) przyswojenia anomalii i wykorzystania jej na użytek własnej kultury ${ }^{76}$. Ponadto antropologia kulturowa umożliwia badanie relacji kultury dominującej wobec kultur niepełnosprawności i ich członków czy też w perspektywie wewnętrznej, dotyczącej struktur, procesów wewnętrznych różnych kultur niepełnosprawności.

\section{Aspekt trzeci}

Antropologia kulturowa uwzględnia dzięki najczęściej stosowanym strategiom badań terenowych, obserwacji uczestniczącej i metodzie etnograficznej, dochodzenie i procedowanie badawcze indukcyjne oraz tworzenie teorii kulturowej studiów nad niepełnosprawnością. Ponadto to właśnie badania etnograficzne, zdaniem Michaela Angrosino 77 - antropologa kultury badającego problematykę dorosłości, seksualności i deinstytucjonalizacji osób z niepełnosprawnością intelektualną - są odpowiednie do studiowania zachowań społecznych lub zagadnień, które nie zostały jeszcze w pełni wyjaśnione.

\section{Aspekt czwarty}

Antropologia kulturowa w etnograficznym wymiarze empirii, uwzględnia dwie płaszczyzny prowadzenia badań: emiczną (wewnętrzną), czyli z perspektywy uczestników sceny kulturowej i etic (zewnętrzną), czyli przefiltrowaną dogłębnie przez badacza. Przy czym perspektywa emiczna oddaje głos uczestnikom kultur niepeł-

${ }^{76}$ M. Douglas, op. cit., s. 79.

77 M. Angrosino, Badania etnograficzne... 
nosprawności, co jest z kolei kluczowe w epistemologii studiów nad niepełnosprawnością ${ }^{78}$.

\section{Aspekt piaty}

Antropologia w wymiarach praktyki badawczej autoetnografii daje szansę uczestnikom scen kulturowych niepełnosprawności, niekoniecznie profesjonalnym badaczom $\mathrm{z}$ niepełnosprawnością, aby stali się badaczami własnej kultury. Przykłady prowadzonych badań opublikowałam w artykule o autoetnografii z 2009 r.79. Inna opcja, podkreślana przez Davida Hershensona, dotyczy sytuacji, gdy dzięki tak pomyślanym badaniom selfowym, antropolog kultury z niepełnosprawnością może prowadzić badania antropologiczne w ramach studiów nad niepełnosprawnością, w kontekstach własnej kultury ${ }^{80}$. Taką badaczką jest m.in. Amerykanka Devva Kasnitz, antropolog kultury, socjolodzy Colin Barnes, Tom Shakespeare.

\section{Aspekt szósty}

David Hershenson ${ }^{81}$ w końcowej części artykułu przedstawia pytania, które powinny być jego zdaniem postawione w konstruowaniu badań etnograficznych w ramach antropologicznych studiów nad niepełnosprawnością. Autor zaleca zwrócenia uwagi i poznanie:

- Czy istnieje koncepcja niepełnosprawności w kulturze?

- Jeśli tak, co konstytuuje bycie niepełnosprawnym?

- Jeśli niepełnosprawność istnieje jako koncepcja w kulturze, to w jaki sposób kultura wskazuje, że w członkowie kultury powinni działać czy zachowywać się (włączając reakcje i uczucia) wobec osób, które są kategoryzowane jako niepełnosprawne?

- Jakie struktury (np. idee, zachowania, obiekty materialne, artefakty) istnieją $\mathrm{w}$ kulturze $\mathrm{w}$ celu promowania lub wzmac-

78 B. Borowska-Beszta, Etnografia stylu życia kultury dorostych...

79 B. Borowska-Beszta, W tym cieniu jest tyle stońca. Autoetnografia, „Pedagogika Kultury" 2009, t. 5, s. 81-96.

80 D. Hershenson, Toward a Cultural Anthropology of Disability and Rehabilitation, “Counseling Bulletin” 2000, 43(3), s. 150-157.

81 Ibidem. 
niania kulturowo akceptowanych sposobów zachowania wobec osób z niepełnosprawnością?

- Jakie struktury istnieją w kulturze w celu ułatwiania funkcjonowania osobom z niepełnosprawnością?

- Czy koncepcja niepełnosprawności obecna w danej kulturze prowadzi do koncepcji rehabilitacji czy nie? (W nazistowskich Niemczech, pisze David Hershenson, niepełnosprawność była rozpoznawana i miała status oraz koncepcję, która nie prowadziła do koncepcji rehabilitacji lecz do koncepcji eksterminacji). Moim zdaniem, analogicznie można by zapytać, jaka jest status i koncepcja niepełnosprawności w dominującej kulturze polskiej lat 2016-2017?

- David Hershenson kontynuuje pytania i zaleca, aby postawić również pytanie badawcze o to: jak jest postrzegana koncepcja pracy $\mathrm{w}$ danej kulturze, (np. istotna do fizycznego przetrwania, duchowego zbawienia lub nie jest moralną koniecznością) i w jaki sposób te koncepcje oddziałują na koncepcje rehabilitacji (społecznej) osób z niepełnosprawnością?82

\section{Kontekst retoryczny}

Antropologiczne badania nad niepełnosprawnością nasycone są dwugłosem z silnym akcentem i ekspozycją w raportach danych verbatim i wewnętrznego głosu z terenu. Dodatkowo niekiedy pojawia się specyficzna retoryka literacka, dotycząca kataklizmów, wojen, retoryka mediów, retoryka osobista weteranów, retoryka opresyjnego stosunku kultur do fenomenu niepełnosprawności.

\section{Kontekst polityczny}

Badania antropologiczne są niekiedy uwikłane w wątki i konteksty polityczne, gdy prowadzone są $\mathrm{w}$ modelu partycypacyjnych ba-

82 Ibidem, s. 150-157. 
dań w działaniu (action research). Bywa, że są prowadzone przez uczonych aktywistów zasilających fundacje, stowarzyszenia i towarzystwa oraz reprezentują głos, potrzebę zmian i interesy studiowanej grupy. Sam wątek wymagałby osobnego omówienia ze względu na złożoność i problemów epistemologicznych, etycznych, które się w tle ujawniają. Chcę jednakże powiedzieć za Susan Wendell ${ }^{83}$, że nie jest bez znaczenia: kto definiuje niepetnosprawność i co ma na celu? A dowody zarówno pozytywne i negatywne mamy zwłaszcza w historii współczesnej, historii najnowszej dotyczącej kulturowej kontroli fenomenu niepełnosprawności, na drodze praktyk eugenicznych ${ }^{84}$. Niekiedy jednak to badacz, antropolog kultury, który nie jest aktywistą, może również dokonać pozytywnych zmian w badanej scenie kulturowej i rozwiązać palące problemy. Jednym z nich może być przykład wskazany niegdyś przez Jamesa Spradleya ${ }^{85}$ i dotyczący zaspokojenia interesów i potrzeb uczestników badań, rdzennych mieszkańców Stanów Zjednoczonych. Chodziło o redukcję alkoholizmu w plemieniu Indian z Ameryki Północnej, oprócz realizacji badań etnograficznych w danym plemieniu. Ponadto wątki i uwikłania polityczne ujawniają się $\mathrm{w}$ tle prowadzenia antropologicznych badań edukacyjnych w działaniu, w celach emancypacyjnych i dokonania zmian edukacyjnych oraz społecznych, które promuje na gruncie polskim Hana Červinková86. Autorka dostrzega w antropologii edukacyjnej siłę sprawczą i pozytywne skutki zaangażowanej antropologii edukacyjnej, wspierającej jej zdaniem procesy demokratyczne na drodze emancypacji dzięki pracom badawczym antropologów.

Hana Červinková, pisze:

antropologia edukacyjna $\mathrm{w}$ inspirujący sposób łączy tradycje pedagogiczne i antropologiczne, a w kontekście omawianej tu problematyki

83 S. Wendell, The Rejected Body. Feminist Philosophical Reflections on Disability, Routledge, New York 1996, s. 23.

84 B. Borowska-Beszta, Aborcja eugeniczna...

85 J. Spradley, The Ethnographic interview, Holt, Rinehart and Winston, New York 1979.

${ }^{86} \mathrm{H}$. Červinková, Badania w działaniu $i$ zaangażowana antropologia edukacyjna, „Teraźniejszość - Człowiek - Edukacja” 2012, 1(57), s. 7-18. 
najbardziej inspirująca jest praca tych antropologów, którzy jako edukatorzy pomagają ludziom $\mathrm{w}$ upełnomocnieniu i emancypacji poprzez stosowanie w różnych projektach edukacyjnych „pedagogiki demokracji", wpisującej w prowadzenie badań w działaniu metody typowe dla etnografii ${ }^{87}$.

Autorka postrzega antropologów edukacji jako kreatorów zmian edukacyjnych. Nie jest to jedyny sposób konceptualizowania badań antropologicznych w edukacji, jednakże idąc tym tropem, można zapytać, jakie polityczne znaczenia i wartość emancypacyjną mają dla studiów nad niepełnosprawnością badania w działaniu oparte na obserwacji uczestniczącej, badaniach etnograficznych? Moim zdaniem mają istotne, gdyż zaangażowane studia nad niepełnosprawnością prowadzone zgodnie $\mathrm{z}$ epistemologią antropologii kulturowej zostaną skonfrontowane teoretycznie i empirycznie, $\mathrm{z}$ co najmniej trzema opisanymi teoretycznie koncepcjami oraz opresjami kulturowymi, stanowiącymi jednocześnie problemy istniejące w kulturze dominującej, w kontekście teoretyzowania cielesności osób z niepełnosprawnością i poważnych jej implikacji. Wśród nich chcę wskazać:

- hegemoniczny ableizm - opisany przez Ronalda Bergera jako ableizm, który „zakłada, że niektórzy ludzie (i ich ciała) są 'normalne' i nadrzędne w stosunku do innych ludzi (i ich ciał), które są nienormalne i podrzędne, a to wzmaga instytucjonalną dyskryminację opartą na różnicach" 88 ;

- ideologie niepetnosprawności - opisaną przez Tobina Siebersa, który zauważa, że „ideologia niepełnosprawności, jest najprostszą formą preferencji pełnosprawności rozumianej jako cielesności lecz w najbardziej radykalnej formie, definiuje podstawy determinowania człowieczeństwa, ustalając podstawy szacowania i oceny ciała i umysłu, co nadaje lub odbiera status człowieczeństwa danej indywidualnej osobie" ${ }^{\prime \prime}$;

87 Ibidem, s. 13

88 R.J. Berger, op. cit., s. 8.

89 T. Siebers, Disability Theory, The University of Michigan Press, Ann Arbor 2008 , s. 8. 
- kulturowa kontrola niepetnosprawności - opisaną jako kulturowa kontrola anomalii przez Mary Douglas ${ }^{90}$, której prowadzenie za pomocą praktyk eugenicznych i instrumentu, jakim jest aborcja eugeniczna "głęboko uszkodzonych i zdeformowanych płodów" - opisała Beata Borowska-Beszta ${ }^{91}$.

Wskazane powyżej trzy grupy problemów teoretycznych dotyczących cielesności i niepełnosprawności mających implikacje na planie społecznym i kulturowym niewątpliwie wymagają od badaczy antropologów kultury zaangażowanych postaw badawczych w kierunku zmian społecznych. W tym kontekście bardzo aktualne jest nadal pytanie H. Beckera92, po której stronie jest badacz kultury? Kolejne pytanie istotne dotyczy tego, czy jest po stronie beckerowskiego underdoga w dążeniach do zmian? - albo po której stronie w ogóle jest?

\section{Konkluzja}

Analizy w powyższym artykule dotyczyły wkładu antropologii kulturowej w studia nad niepełnosprawnością. O ile czytelne są drogi ewolucji konstytuowania przez antropologów kultury przedmiotu badań antropologicznych, można by postawić dodatkowe pytanie: jaki związek mogą mieć i mają powyższe osiągniecia antropologów kultury z pedagogicznymi studiami nad niepełno-sprawnością? Otóż, moim zdaniem, pedagogiczne studia nad niepełnosprawnością mogą być i są prowadzone z perspektywy antropologii kulturowej, uwzględniając zarówno osiągnięcia antropologów w badaniach nad niepełnosprawnością, jak i epistemologiczny kontekst badań i tzw. myślenie antropologiczne opisane przez Philipa C. Salzmana, Patricię C. Rice ${ }^{93}$ czy Bartłomieja Walczaka94. Konklu-

${ }^{90}$ M. Douglas, op. cit.

91 B. Borowska-Beszta, Aborcja eugeniczna...

92 H. Becker, Whose Side Are We On?, "Social Problems”, Winter 1967, Vol. 14, No. 3, s. 239-247.

93 P.C. Salzman, P.C. Rice, Myśleć jak antropolog, GWP, Gdańsk 2009. 
dując analizy ram przedmiotu interdyscyplinarnie konceptualizowanych studiów nad niepełnosprawnością prowadzonych w pedagogice specjalnej, chciałabym zauważyć pewną prawidłowość polegającą na tym, że zdarza się, że nazwa studia nad niepetnosprawnością, staje się dla pedagogów specjalnych nośnym i atrakcyjnym modelem prowadzenia badań społecznych, kulturowych w Polsce, lecz istnieje niekiedy jedynie w warstwie deklaratywnej akademików, pedagogów specjalnych wobec zupełnie innej rzeczywistości i paradygmatów badawczych, w których dani akademicy istnieją. Jeśli bowiem akademicy deklarujący prowadzenie studiów nad niepełnosprawnością pomijają społeczne i kulturowe konstrukty oraz modele niepełnosprawności, a prowadzą $\mathrm{w}$ istocie badania $\mathrm{w}$ modelu klinicznym zorientowane na terapię i naprawczość, można mieć pewność, że w żadnym razie nie realizują studiów nad niepełnosprawnością, mimo uprzednich deklaracji.

\section{Bibliografia}

Ablon J., Little people in America: The social dimensions of dwarfism, Praeger, New York 1984.

Ablon J., Living with difference: Families with dwarf children, Praeger, New York 1988.

Angrosino M., Opportunity House: Ethnographic Stories of Mental Retardation, Altamira Press, Walnut Creek 1998.

Angrosino M., Badania etnograficzne i obserwacyjne, PWN, Warszawa 2010.

Angrosino M., The Ethnography of Mental Retardation: An Applied Perspective, "Journal of Contemporary Ethnography" 1997, 26(1).

Angrosino M., Metaphors of Stigma: How Deinstitutionalized Mentally Retarded Adults

See Themselves, "Journal of Contemporary Ethnography" 1992, 21(2).

Angrosino, M., Badania etnograficzne i obserwacyjne, PWN, Warszawa 2010.

Barnes C. , Disability Studies: what's the point? (Notes for a verbal presentation at the 'Disability Studies: Theory. Policy and Practice' Conference; University of Lancaster, September 4th. 2003), http://disability-studies.leeds.ac.uk/files/library/ Barnes-Whats-the-point.pdf s. 10 [dostęp: 7.04.2016].

94 B. Walczak, Antropolog jako inny. Od pierwszych badań terenowych do wyzwań ponowoczesnej antropologii, Wydawnictwo Naukowe Scholar, Warszawa 2009. 
Barnes C., Disabling Imagery And The Media. An Exploration of the Principles for Media Representations of Disabled People. http://disability-studies.leeds.ac.uk/files/lib rary/Barnes-disabling-imagery.pdf, 1992 [dostęp: 7.04.2016].

Barnes C., Mercer G., Disability Culture: Assimilation or Inclusion?, [w:] red. G.L. Albrecht, K. Seelman, M. Bury, Handbook of Disability Studies, Sage Publications, Inc. London, Londyn 2001.

Barnes C., Mercer G., Niepetnosprawność, Wydawnictwo Sic!, Warszawa 2008.

Battles H., Toward Engagement: Exploring the Prospects for an Integrated Anthropology of Disability, "vis-à-vis: Explorations in Anthropology" 2011, Vol. 11, No. 1.

Becker H., Whose Side Are We On?, „Social Problems” Winter 1967, Vol. 14, No. 3.

Benedict R., Anthropology and the Abnormal, "Journal of General Psychiatry" 1934, No. 10.

Berger R.J., Introducing Disability Studies, Lynne Rienner Publishers, London 2013.

Borowska-Beszta B., Aborcja eugeniczna (aborcja ze względu na niepetnosprawność) w opiniach polskich studentów studiów uniwersyteckich II. stopnia na kierunku pedagogika specjalna: Raport z etnograficznego studium przypadku [Raport z badań w toku wydawniczym].

Borowska-Beszta B., Etnografia stylu życia kultury dorostych torunian z zaburzeniami rozwoju, Wydawnictwo Naukowe UMK, Torun 2013.

Borowska-Beszta B., Kultury niepetnosprawności w kontekstach teoretycznych i realiach badawczych - szkice analizy strukturalnej http://www.pion.pl/artykuly/czytelnia/ kultury-niepelnosprawnosci-w-kontekstach-teoretycznych-i-realiach-badawczychszki, 2014 [dostęp: 30.04.2016].

Borowska-Beszta B., Metodologiczne konteksty badań kulturowych w obszarze andragogiki specjalnej, „Rocznik Andragogiczny” 2009, 16.

Borowska-Beszta B., Niepetnosprawność w kontekstach kulturowych i teoretycznych, Impuls, Kraków 2012.

Borowska-Beszta B., W tym cieniu jest tyle stońca. Autoetnografia, „Pedagogika Kultury" 2009, t. 5.

Brown S.E., What Is Disability Culture?, "Disability Studies Quarterly" Spring 2002, Volume 22, No. 2, s. 34-50, www.dsq-sds.org Society for Disability Studies [dostęp: 30.04.2016].

Červinková H., Badania w działaniu i zaangażowana antropologia edukacyjna, "Teraźniejszość - Człowiek - Edukacja” 2012, 1(57).

Cimpric A., UNICEF WCARO, Dakar https://www.unicef.org/wcaro/wcaro_chil dren-accused-of-witchcraft-in-Africa.pdf April 2010 [dostęp: 7.04.2017].

Edgerton R.B., A Patient Elite: Ethnography in a Hospital for the Mentally Retarded, “American Journal of Mental Deficiency" 1963, Nr 68.

Edgerton R.B., The Cloak of Competence: Stigma in the Lives of the Mentally Retarded, University of California Press, Berkeley 1967. 
Fries K., Staring back: The disability experience from the inside out, Plume, New York 1997. Goodley D., Disability Studies. An Interdisciplinary Introduction, Sage, London 2011.

Guba E., Lincoln Y.S., Competing paradigms in qualitative research, [w:] N.K. Denzin, Y.S. Lincoln (red.), Handbook of qualitative research, CA Sage, Thousand Oaks 1994.

Hanks J.R., Hanks L.M., The Physically Handicapped in Certain Non-Occidental Societies, "Journal of Social Issues" 1948, Vol. 4, Issue 4.

Hershenson D., Conceptions of Disability: Implications for Rehabilitation, "Rehabilitation Counseling Bulletin" 1992, 35(3).

Hershenson D., Toward a Cultural Anthropology of Disability and Rehabilitation, "Counseling Bulletin" 2000, 43(3).

IDA submission for the joint General Comment/Recommendation of the Committee on the Rights of the Child and the Committee on the Elimination of Discrimination against Women on harmful practices, http://www.ohchr.org/Documents/ HRBodies/CEDAW/HarmfulPractices/InternationalDisabilityAlliance.pdf [dostęp: 7.04.2016].

Ingstad B., Whyte S.R., Disability in Local and Global Worlds, Univ. Calif. Press, Berkeley 2007.

Kassnitz D., Switzer M., Shuttleworth R., Introduction: Anthropology in Disability Studies, “Disability Studies Quarterly" Summer 2001, Volume 21, No. 3, www.dsq-sds.org Society for Disability Studies.

Klotz J., The Culture Concept: Anthropology, Disability Studies and Intellectual Disability. Paper presented to Disability Studies and Research Institute Symposium, "Disability at the Cutting Edge: A Colloquium to Examine the Impact on Theory, Research and Professional Practice", University of Technology, 2003, http://www.transforming. cultures.uts.edu.au/pdfs/new_paths_klotz.pdf [dostęp: 7.04.2017].

Kumaniecka-Wiśniewska A. Kim jestem? Tożsamość kobiet upośledzonych umystowo, Wydawnictwo Akademickie Żak, Warszawa 2005.

Kumar V., Anthropological Perspective of Disability, "International Journal of Information Research and Review" 2016, Vol. 03, Issue, 02.

McDermott R., Varenne H., Adam, Adam, Adam, and Adam: The Cultural Construction of a Learning Disability, [w:] Successful Failure: The School America Builds, red. H. Varenne, R. McDermott, CO: West-view Press, Boulder 1999.

Oswajanie odmienności psychosomatycznej. 11 Raportów z polskich jakościowych badań pedagogicznych $i$ andragogicznych, red. B. Borowska-Beszta, WBW Omniscriptum, Saarbrucken 2016.

Pękala-Gawędzka D., Antropologia medyczna a etnofarmakologia, „Lud” 1994, t. 77.

Perzanowski A., Odmieńcy. Antropologiczne studium dewiacji, Wydawnictwo DiG, Warszawa 2009.

Rzepkowska A., Zespół Aspergera - społeczno-kulturowe konsekwencje diagnozy, „Zeszyty Wiejskie" 2014, t. 19. 
Salzman P.C., Rice P.C., Myśleć jak antropolog, GWP, Gdańsk 2009.

Shakespeare T., Cultural representations of disabled people: dustbins for disavowal?, "Disability and Society" 1994, 9(3).

Shakespeare T., The Disability Reader: Social Science Perspectives, Cassell, London 1998.

Shakespeare T., Watson N., The social model of disability: an outdated ideology?, "Journal Research in Social Science and Disability" 2002, Vol. 2.

Shuttleworth R., Kasnitz D. Stigma, community, ethnography: Joan Ablon's contribution to the anthropology of impairment/disability, "Medical Anthropology" 2004, 18(2).

Siebers T., Disability Theory, The University of Michigan Press, Ann Arbor 2008.

Snyder S.L., Mitchell D.T., Cultural Locations of Disability, University of Chicago Press, Chicago 2006.

Spradley J., The Ethnographic interview, Holt, Rinehart and Winston, New York 1979.

Taylor S., Shoultz B., Walker P., Disability studies: Information and Resources, http://thechp.syr.edu/wp-content/uploads/2013/10/Disability_Studies_2003_ current.pdf [dostęp: 7.04.2016].

Walczak B., Antropolog jako inny. Od pierwszych badań terenowych do wyzwań ponowoczesnej antropologii, Wydawnictwo Naukowe Scholar, Warszawa 2009.

Wendell S., The Rejected Body. Feminist Philosophical Reflections on Disability, Routledge, New York 1996.

Zakrzewska-Manterys E., Down i zespót wątpliwości. Studium z socjologii cierpienia, Wydawnictwo Naukowe Semper, Warszawa 1995.

Zakrzewska-Manterys E., Upośledzeni umysłowo. Poza granicami człowieczeństwa, Wydawnictwo Naukowe UW, Warszawa 2010. 